\title{
Analysis of the Prevalence \& Implications of Sexual Abuse among Children: A Study among Healthcare Givers at GVRC Nairobi Women's Hospital, Nairobi County, Kenya
}

\author{
JULIA ADHIAMBO JUMA ${ }^{1}$, DANIEL K KIMWETICH ${ }^{2}$, PAUL CHANDOO MUSANGO ${ }^{2}$ and \\ DAVID NZIOKA MUTISYA ${ }^{3}$ \\ ${ }^{1}$ Africa Nazarene University \\ ${ }^{2}$ Management University of Africa \\ ${ }^{3}$ Moi University
}

Kenya

\begin{abstract}
This study set to establish the prevalence of sexual abuse among children survivors attended to at GVRC Nairobi Women's Hospital in Nairobi County. Sexual abuse among children is a universal problem and one of the most pervasive human rights violations. Child sexual abuse among children in Kenya has been increasing at an alarming rate in the recent past. Sexually abused children are denied their right to enjoy their fundamental freedom and grow up as normal children in society. This study was guided by the Traumagenic Dynamic Model of child sexual abuse. The study adopted an explanatory research design where 80 healthcare givers who were purposively sampled participated and document analysis of 4332 children who had been sexually abused in the last two years preceding this study. Data was collected through structured interview guides and document analysis from the hospital records. Piloting was done to establish its reliability and validity. Descriptive statistics comprising of frequencies, percentages, means and standard deviations were used to analyze data and the findings were presented in line with the study objective which were: 1.identify the perpetrators of sexual abuse among children. 2. Explore risk factors that lead to sexual abuse among children. 3. Establish the prevalence of sexual abuse among children. There were 4332 cases of sexual abuse among children out of 7558 cases for the whole population reported in the two years preceding the study, which translates to a prevalence rate of 57.3\%. These findings revealed that the prevalence of sexual abuse among children attended to at the hospital was high. To this end, 2115 cases were handled in 2015-2016 (48.82\%) and 2217 (51.18\%) in 2016-2017. This makes a total of 4332 cases handled during the period. Key recommendations from the study included: Need for multi-faceted approach involving key stakeholders to be adopted with a view of reducing the high prevalence of sexual abuse among children survivors; the need for all stakeholders who handle children issues to ensure that stringent measures are put in place for the prevention and control of CSA among the survivors; and the need to change the approaches and engagement of all stakeholders who deal with children by spreading the message that would make the society aware of the alarming rate of CSA in Kenya today.
\end{abstract}

Keywords: Sexual Abuse, Prevalence, Survivors, Traumagenic Dynamic Model, Multi-faceted approach, Stakeholders, Alarming, Violations.

\subsection{INTRODUCTION}

The World Health Organization (WHO, 2006) defined child sexual abuse (CSA) as the involvement of a child in sexual activity that he or she does not fully comprehend and is unable to give informed consent to, or for which the child is not developmentally prepared for. CSA is a global problem often defying myths and stereotypes and does not appear to be decreasing over time. According to Sullivan (2002), it takes the form of rape, defilement, incest, sodomy, assault or violation. CSA also includes the use of children for sexual pleasure and satisfaction by an adult. According to a study by Fishbein and Ajzen (2005) in 
Massachusetts in the United States of America (USA), the behavior of children towards sexual abuse is determined by the significant others in their lives. As a result, their reaction towards such abuse is influenced by the expectations of these people. In light of this, sexual abuse against children may go on unabated without the knowledge of anybody else. Statistics by the United Nations Children's Fund (UNICEF, 2012) show that annually, 65\% of children are sexually abused.

A study by the Ministry of Women and Children Development, Government of India (2007) indicated that the subject of CSA is still a taboo. Out of 2211 respondents, $42 \%$ of the children faced at least one form of sexual abuse. There seems to be a conspiracy of silence around the subject of CSA in India and a very large percentage of people feel that this is a western problem that does not happen in India. One of the reasons could be that traditionally, India's conservative family and community structure does not allow its people to talk about sex and sexuality openly. The report further says that parents usually do not speak to their children about sexuality as well as physical and emotional changes in their bodies during their growth. As a result of this, CSA go unreported.

The UNICEF (2001) confirmed that there is an overwhelming amount of evidence showing that the problem of sexual abuse including commercial sexual exploitation of children in the Sub-Saharan Africa (SSA) is an extensive problem (WHO, 2016). Children are sexually abused and exploited in the home, school, community, workplace and brothels. It is also clear that the HIV/AIDS pandemic is both a cause and consequence of sexual exploitation of children in the region. This emanates from existent myths that HIV positive people can be cleansed by having unprotected sex with a child or a virgin (WHO, 2016). A study of CSA in South Africa by Jaffe and Roux (1988) examined 88 cases in the Teddy Bear Clinic for Abused Children. The study noted that there were increased numbers of sexually abused children presented in the hospital. Of these 88 children, $90 \%$ were female in the 4 to six-year-old age group.

A study in Uganda by UNICEF (2013) indicated that CSA has remained high (at 81\%). This is confirmed by studies by ANPPCAN (2011) which concur with the annual crime report of the World Health Organization. A WHO (2016) report indicated that in Kenya, CSA cases have been on the increase with statistics showing a 38.9\% increase between 2011 and 2012 . This confirms that in Kenya, the situation is seen to be worsening. Data from the Child Protection Report (2006-2013) as published by UNICEF (2013) established that more than 33,929 cases of CSA have been reported in Kenya within the study period. Of these cases, 7,832 were of sexual abuse. This alarming rate clearly calls for extensive, powerful policies and efforts. According to a report by Justice Chambers and Care Kenya (2014), rape cases in the country rose by 50\% between 2009 and 2014 . Most of these cases were in slum areas of Nairobi. Karimi (2005) pointed out that these offenders might be normal persons or those with psychiatric disorders.

The Nairobi Women's Hospital Gender Violence Recovery Center (2012) statistics indicated that there is high prevalence of sexual abuse targeting children in Kenya. Currently, around 270 survivors are treated monthly at the hospital. Makhija (2014) posited that though CSA has received media coverage, many individuals and child care professionals are still in denial of the scope and the severity of this great problem which cuts across a wide range of social, cultural and socio-economic boundaries. It violates the fundamental human rights of children and in most cases leads to serious injury or death. Although statistics vary slightly, children are survivors of sexual abuse in approximately 65\% of the reported cases (Karimi, 2005).

\subsection{METHODOLOGY}

The study adopted an explanatory research design where healthcare givers who were purposively sampled participated and document analysis of sexually abused children in the last two years preceding this study was carried out. The researchers managed to obtain responses from 64 healthcare givers, thus a response rate of $80 \%$. Data was collected through structured interview guides and document analysis from the hospital records. Piloting was done to establish reliability and validity of the data collection instruments. Data was cleaned, coded and analyzed using the Statistical Package for Social Sciences (SPSS), Version 24. Descriptive statistics comprising of frequencies and percentages were used to analyze data and the findings were presented in line with the study objective namely: to establish the prevalence of sexual abuse among children survivors attended to at GVRC Nairobi Women's Hospital in Nairobi County.

Explanatory research design mainly establishes the extent and nature of cause and effect relationships. This study was designed using quantitative and qualitative research designs. It gave insight on the prevalence of CSA among Children seeking treatment at GVRC Nairobi Women's Hospital, Nairobi County, Kenya. The study sought to explore the extent of the problem in Nairobi County for the past two years. As such, data was collected from the medical records and by interviewing hospital staff who dealt with child survivors of sexual abuse.

The Nairobi Women's Hospital has a general population of 500 staff members. The study targeted 80 members of staff who handled cases of sexual abuse among children. The researcher purposively involved only the staff members who dealt with CSA in the Centre. These included 20 counselors, 15 social workers, 30 nurses and 15 medical directors. These were involved because they were deemed best suited to deal with the investigation subject, while the survivors' records (records between 2015 and 2017) provided most of the required data. 
Purposive sampling was used to select the 80 health care givers who participated in this study while a census was used for the 4,332 cases of child sexual abuse reported in the hospital for the two-year period from the document analysis. The study used total population of medical staff working at the center and who handled children who had been sexually abused. In this study, all the staff who handled the sexually abused children and medical records targeted by the study was sampled. The sample breakdown is as shown in Table 1.

Table 1: Study Sample Size

\begin{tabular}{|c|c|}
\hline Category & Sample (n) \\
\hline Health care givers & Number \\
\hline Counselors & 20 \\
\hline Social workers & 15 \\
\hline Nurses & 30 \\
\hline Medical Directors & 15 \\
\hline Total & 80 \\
\hline
\end{tabular}

Secondary data about the 4,332 children who had been sexually abused and attended to at the hospital for a period of two years preceding the study was also used. They were aged between 3 and 18 years. Cases reported in the year 2015-2016 were 2115 while those reported in the year 2016-2017 were 2217.

The data generated through the questionnaire was checked, edited, organized and coded using numbers to specific responses. This was aimed at making data entry easier. The coded data was then analyzed using Statistical Package for Social Science Programme (SPSS), Version 24. Descriptive statistics comprising mainly of frequencies and percentages were used to analyze data. The findings obtained were presented in form of tables and figures and conclusions drawn.

\subsection{RESULTS}

This section presents the number of CSA cases handled in the hospital during the two-year period preceding the study, frequency, treatment received; other types of support given and; the time the survivors sought medical help after the sexual abuse. Data was collected from 60 out of a sample of 80 Care givers. Furthermore, information on these aspects was also established from the document analysis. Findings from document analysis revealed that cases of children attended to at the Hospital have been on the increase in the last two years.

Table 2: Prevalence of Sexual Abuse among Children

\begin{tabular}{|l|c|c|}
\hline \multicolumn{1}{|c|}{ Years } & $\begin{array}{c}\text { N (Number of } \\
\text { cases) }\end{array}$ & Percentage \\
\hline $2015-2016$ & 2115 & 48.82 \\
\hline $2016-2017$ & 2217 & 51.18 \\
\hline Total & 4332 & 100.00 \\
\hline
\end{tabular}

Document analysis revealed that many of the cases handled over the two-year period were new sexual abuse cases with 2115 cases reported in 2015-2016 and 2217 (51.18\%) cases handled in 2016-2017 thus a total of 4332 cases handled during the period, as presented in Table 3. The 4332 cases of sexual abuse among children out of the total population of 7558 cases for the whole population during the same period translate to a prevalence rate of $57.3 \%$. The findings agrees with a report published by Justice Chambers and Care Kenya (2014) in which rape cases in Kenya were reported to have risen by $50 \%$ between 2009 and 2014.The high prevalence of CSA as shown from this study confirms the survey by Kenya Social Protection (2014) that was concerned that CSA situation seems to be worsening in Kenya. Comparing this study with the report by UNICEF (2013) which indicated that CSA rate was at $81 \%$ in a study done from 2009 to 2014 , it is therefore evident that four years down the line the rates of the prevalence of CSA is still high at $57.3 \%$ as shown by this study.

The high prevalence shows that there are wide incidences of CSA among children regardless of the many measures and laws regarding children's rights put in place in the Kenyan constitution. With all these laws in place, the rate should have been lower than $57.3 \%$. From the study findings, it could be that CSA has not been given extensive attention due to culture and stigma as confirmed by WHO (2006) report that indicated that despite CSA being a crime in most countries, and with well-known 
physical and mental health consequences, it is still evident in our society today and yet many cases are not reported due to stigma, culture and lack of awareness of children, as well as intimidation from the abuser or their families. Children sexual abuse has been rampant in the recent past given that the number of cases reported was high. A total of 7558 cases were therefore handled in the last two years. This is in line with the Nairobi Women's Hospital GVRC (2012) statistics which revealed a high prevalence of sexual abuse targeting children in Kenya.

Table 4: Number of Times Sexual Abuse among Children Occurred According to Care Givers

\begin{tabular}{|l|l|l|}
\hline Number of times & $\begin{array}{l}\text { N (Number of } \\
\text { cases) }\end{array}$ & Percentage \\
\hline Once & 24 & 40 \\
\hline Twice & 9 & 15 \\
\hline 3-5 times & 12 & 20 \\
\hline More than 5 times & 15 & 25 \\
\hline Total & 60 & 100 \\
\hline
\end{tabular}

The care givers were asked to indicate the number of times sexual abuse among children occurred as presented in Table 4. The analysis revealed that $40 \%$ of the sexual abuse cases occurred once, $25 \%$ occurred more than 5 times, $20 \%$ occurred between 3-5 times, while the remaining 15\% occurred twice. This reveals that a significant number of cases occurred more than once; an indication that children are being abused often. In this light, these findings agree with Krug, et al. (2002) that stated sexual abuse against a child may go on unabated without anybody else knowing.

Table 5: Treatment Received According to Care Givers

\begin{tabular}{|l|c|c|}
\hline & N (Number of cases) & Percentage \\
\hline Outpatient & 33 & 55 \\
\hline Inpatient & 27 & 45 \\
\hline Total & 60 & 100 \\
\hline
\end{tabular}

The study sought to establish from care givers the treatment received at the hospital. The findings obtained revealed that $33(55 \%)$ of the children attended to at the hospital received outpatient treatment, while 27(45\%) received in-patient treatment as shown in Table 5. The treatment received shows that there is a balance between outpatient cases for those who do not acquire major injuries at $55 \%$, while those admitted in hospital due to major injuries that would require surgery and other medical attention are at $45 \%$. These findings are in line with the GVRC manual (2012) that states that the hospital has ensured that facilities are equipped with skilled health providers, medical supplies, and equipment.

Table 6: Other Types of Support Given According to Care Givers

\begin{tabular}{|l|l|l|}
\hline & N (Number of cases) & Percentage \\
\hline Psychosocial & 9 & 15 \\
\hline Child protection & 15 & 25 \\
\hline Legal & 36 & 60 \\
\hline Total & 60 & 100 \\
\hline
\end{tabular}

The study established that there were other types of support given to the sexually abused children which included legal support services at 36(60\%); child protection services at 15(25\%); and psychosocial services at 9(15\%) as shown in Table 6. This therefore shows that the main form of support provided to the children was legal support at $60 \%$. Regrettably, children protection and psychosocial support only accounted for $25 \%$ and $15 \%$ respectively. This shows that victims of CSA were not receiving adequate psychosocial support. This corroborates the findings of McCrann (2006) who stated clearly that often psychological needs of survivors of CSA are overlooked even in settings that offer medical services 
Table 7: When the Abused Children Sought Medical Help

\begin{tabular}{|c|c|}
\hline Time & \% \\
\hline Within 24 Hrs & 11.3 \\
\hline Within 48 Hrs & 27.4 \\
\hline Within 72 Hrs & 45.8 \\
\hline After 72 Hrs & 15.5 \\
\hline Total & 100 \\
\hline
\end{tabular}

Medical records were analysed to ascertain when the sexually abused children sought medical help from them. Results presented in Figure 7 show that $45.8 \%$ of the children sought services within 72 hours, $27.4 \%$ within 48 hours, $15.5 \%$ after 72 hours, while $11.3 \%$ did so within 24 hours. This therefore implies that most of the sexually abused children visit the hospital within the stipulated standard time of 72 hours thus an indicator of high levels of awareness on how to protect self from pregnancy and HIV/AIDS infection as posited by Nita (2014) who says that in the case of a very recent assault a survivor should be given the emotional support but importantly be provided with practical advice about forensic and medical examination among others.

\subsection{CONCLUSION}

Based on the findings, it can be concluded that at $57.3 \%$ of the total population, prevalence of sexual abuse among children in Nairobi is high, given the number of cases reported and their recurrence as confirmed by various scholars. Despite the Kenya Children Act becoming law in 2002 and being operational for the last 16 years, children are still being sexually abused. The Children Act was meant to reduce CSA drastically but with results from the study, questions arise pertaining to children's protection against sexual abuse. As such, practical ways of dealing with sexual abuse should be put in place.

In view of the findings and conclusions of this study, the following recommendations are made: a multi-faceted approach involving key stakeholders should be adopted with a view to reducing the prevalence of sexual abuse among children survivors; and that the government, civil society, community and parents should work hand in hand to ensure that sexual abuses among children are prevented and offenders get severe punishment; The study further suggests that there is need to change approaches and engagement and that all stakeholders who deal with children need to spread the message that would make the society aware of the alarming rate of CSA in Kenya today.

\section{REFERENCES}

[1]. African Network for the Prevention and Protection against Child Abuse and Neglect. (2011). Annual report 2011. Kampala, Uganda: Author.

[2]. American Psychiatric Association. (2013). Diagnostic and statistical manual of mental disorders (5th ed.): DSM-5. Arlington, VA: American Psychiatric Publishing.

[3] . Cantón-Cortés, D., \& Cantón, J. (2010). Coping with child sexual abuse among college students and post-traumatic stress disorder: The role of continuity of abuse and relationship with the perpetrator. Child Abuse \& Neglect, 34(7), 496-506.

[4] . Fishbein, M., \& Ajzen, I. (2005). The influence of attitudes on behavior. London: Open University Press.

[5] . Gender Violence Recovery Centre. (2012). Annual report 2011-2012. Nairobi, Kenya: GVRC.

[6] . Jaffe, A., \& Roux, P. (1988). Sexual abuse of children: A hospital-based study. South African Medical Journal, 74(2):6567.

[7] . Justice Chambers and Care Kenya. (2014). Justice delayed: A status report on historical injustices in Kenya. Nairobi, Kenya: Kenya Human Rights Commission.

[8] . Karimi, E. K. (2005). The role of counseling in rehabilitation of women experiencing domestic violence and other forms of abuse: A case study of women seeking counseling services at Nairobi Women's Hospital (Unpublished master's thesis). University of Nairobi, Nairobi, Kenya.

[9] . Krug, E.G., Mercy, J.A., Dahlberg, L.L., \& Zwi, A.B. (2002) .World report on violence and health. Geneva: World Health Organization.

[10] . Makhija, N. J. (2014). The relationship between traumagenic dynamic responses towards childhood sexual abuse, ethnic identity, social support, trauma severity, and attitudes towards interpersonal relationships in adolescent females (Doctoral dissertation). Retrieved from https://scholarship.shu.edu/cgi/viewcontent.cgi?article=2987 $\&$ context $=$ dissertations 
[11] . McCrann, D., Lalor, K., \& Katabaro, J. K. (2006). Childhood sexual abuse among university students in Tanzania. Child Abuse and Neglect, 30(12), 1343-1351.

[12]. Ministry of Women and Child Development, Government of India. (2007). Study of child abuse in India. New Delhi, India: Author.

[13]. Nita, F. (2014). Child abuse and neglect. New Delhi, India: International Society for Prevention of Child Abuse and Neglect.

[14] . Sullivan, J. (2002). The spiral of sexual abuse: A conceptual framework for understanding and illustrating the evolution of sexually abusive behavior. NOTA News, 41, 17-21.

[15]. The United Nations Children's Fund. (2001). The analysis of the situation of sexual exploitation of children, in the Eastern and Southern Regica Retrieved from https://www .unicef.org/events/yokohama/csec-east-southern-africa-draft.html

[16] . The United Nations Children's Fund. (2012). Children in an urban world: State of the world's children. New York, NY: Author.

[17]. The United Nations Children's Fund. (2013). Children with disabilities: State of the world's children. New York, NY: Author.

[18]. World Health Organization. (2006). Global estimates of health consequences due to violence against children: Background paper to the UN Secretary-General's study on violence against children. Geneva, Switzerland: Author.

[19] . World Health Organization. (2016). World report on violence and health. Geneva, Switzerland: Author. 